The last talk in the first session was titled Tree search in two-player games using bounded common interest to prune and presented by the author, Jeroen Donkers The main question was "how can opponent-modelling be extended so that it includes knowledge symmetry?" The proposed answer is to switch from zero-sum games to non-zerosum games during heuristic search However, there is a problem, namely that those games can have many equilibria that might differ largely The author introduced the concept of 'bounded common interest' that both allows pruning in an alphabeta-like way and that limits the differences between the equilibria The latter element dimınıshes the risk of selectıng a non-optımal equilıbrium

The second session was completely dedicated to computer Go The session stared with a presentation by Ken Chen, author of the paper titled Soft and Hard Connectivity in Go As the title suggests, the author distınguishes two types of connectivity hard connectivity exists if the opponent cannot prevent a player from connectıng to a group, soft connectivity exists if the opponent could prevent connection, but only against high costs The author shows a heuristic based on influence theory to detect soft connectivity To detect the shortest hard-connectivity paths, the author proposed to apply proof-number search variants such as $\mathrm{Pn}+$

The second and the third presentation were both given by Bruno Bouzy He started with the presentation of his own paper History and Territory Heuristic in Monte-Carlo Go In this paper the author presents two heuristics each in two forms internal and external Internal means that the heuristic is used inside the Monte-Carlo simulations External means that the data for the heuristic is collected during the Monte-Carlo simulation, but used in the following pre-selection stage in which moves are selected for the next Monte-Carlo round The territory heuristic uses the average occupation (black / white) for every intersection at the end of the simulations It produces a measure of urgency for moves to play next The history heuristic uses the outcome of the Monte-Carlo simulations (bad or good move) to change the urgency of moves to select next The external territory and external history heuristic appeared to perform best

Bruno Bouzy contınued with the presentation of Tristan Cazenave's paper The Separation Game This presentation fitted well to the first Go paper since a separation is related to the concept of soft and hard connectivity A separation exists if a player can prevent the opponent from connecting two groups It appears that separation exists if there is 8-connectivity So, searching for separation is searching for 8-connectivity The author explains how generalized threat search (GTS) is used to find the important separations Experimental results show that the method increases the search efficiency significantly

The second session was closed by the presentation The Strategies for a Simple One-Point Ko Situation of Computer Go (S J Huang, S S Lin, and S J Yen) given by Sh1-J1e Huang After explainıng the basics of kofight in Go, including ko-threats, the author showed a method to transform the ko-fight into a simpler game by using the values of ko itself, the ko-threats, and other interestıng moves This simplified game can then be solved by a minımax procedure

The two computer-game sessions gave an interestıng and inspirıng insight into the work-in-progress in this area The closing dinner with the participants and the friendly venue of Salt Lake City added to the wonderful experience We thank Ken Chen for organızing this event again

\title{
CALENDAR OF COMPUTER-GAMES EVENTS IN 2006
}

\section{May 25 - June 1, 2006}

The $14^{\text {th }}$ World Computer-Chess Championshıp, Torıno, Italy Information Professor Ciancarını, emaıl cianca@cs unıbo 1t or Johanna Hellemons, email 1nfo@1cga org Http //www 1cga org

\section{May 25 - June 1, 2006}

The $11^{\text {th }}$ Computer Olympıad, Torıno, Italy Information Professor Ciancarını, email cianca@cs unıbo it or Johanna Hellemons, ema111nfo@1cga org Http//www 1cga org

\section{May 29-31, 2006}

The Computers and Games Conference 2006 (CG2006), Torıno, Italy Information Professor Ciancarını, ema1l cianca@cs unibo it or Johanna Hellemons, ema1l 1nfo@icga org Http //www 1cga org

June 9-24, 2006

The 2006 Computer-Bridge Championship will take place as part of the World Bridge Federations's (WBF) World Championships, Verona, Italy Information Mr Al Levy, email Allevy@aol com 